\title{
Forum
}

\section{Captured for conservation: will cages save wild birds? A response to Cooney \& Jepson}

\author{
James D. Gilardi
}

My compliments to Cooney \& Jepson (2006) for raising the issue of the wild bird trade. As they rightly point out, the trade in wild birds has received little scrutiny yet remains a central problem for international bird conservation. Following a comment on the scale of the wild bird trade, I hope to clarify a number of factual difficulties with their article, and then explain why opting out of the bird trade is the most viable remedy to this long-standing and deeply destructive tradition.

The NGO call for an end to the imports of wild birds into the EU is based upon three categorically distinct sets of concerns about the consequences of the wild bird trade: the spread of infectious diseases, impacts on wild bird conservation, and the humane treatment of millions of birds (Wild Bird Declaration, 2004). My comments here will be limited to the conservation impact of the wild bird trade, but with such a complex collection of issues I encourage the interested reader to explore these arguments outlined in the Wild Bird Declaration, and references cited therein.

When it comes to the trade in wild birds, the stakes are extraordinarily high. Over one million exotic birds of $>1,000$ species are legally traded around the world on an annual basis. If trade in non-CITES birds and postcapture mortality are included the number is many times that figure: $5-10$ million birds per year are captured from the wild, primarily for the commercial pet trade.

By definition, these birds are among the most soughtafter species: macaws, cockatoos, flamingos, eagles, toucans and a dazzling array of songbirds. The fact that bird conservation groups care deeply about this issue should come as no surprise to Cooney \& Jepson. The trade not only creates its own conservation crisis, in many cases these traded birds are the very animals that inspired many of us to care about birds, wildlife and nature conservation in the first place. Their demise matters.

Europeans have an added reason for concern because they play a central role in this trade. With a $93 \%$ market share, EU consumers now represent virtually the only players left in this sordid game (SSN, 2004). Where have

James D. Gilardi The World Parrot Trust, Glanmor House, Hayle, Cornwall, TR27 4HB, UK. E-mail gilardi@worldparrottrust.org

Received \& accepted 21 November 2005. all the other consumers of wild birds gone? As it turns out, most buyers outside the EU opted out of the market long ago: Australia halted all imports (and exports) in the late 1950s, and the USA, the largest importer at the time, effectively banned imports in the early 1990s. Many other countries have similar policies.

Concurrently, many exporting countries have prohibited the export and commercial exploitation of their wild birds, notably Brazil, Argentina and, recently, Indonesia. However, a special exception is made by Argentina for agricultural pests; based on scant or no documentation of their pest status many parrots species are listed in this category, and consequently the country is now South America's largest exporter of wild caught birds. Of course, every country in the world has birds that could be easily and profitably exploited, but the vast majority choose not to, including all the 25 members of the European Union. In fact, currently only 15 countries set CITES quotas for wild birds at over 1,000 individuals.

If the EU were to halt imports of wild birds, Cooney \& Jepson would have us believe that 'Northern constituencies' would thereby make demands on 'Southern countries and communities'. This is not so. As EU consumers are driving this destructive, unsustainable and inhumane trade, they should follow the lead of other ethical consumers and opt out of this market entirely. Countries could continue to do what they like with their wild birds, the EU would simply no longer be party to driving their bird populations to the brink of extinction. Lest there be any doubt about the long term impacts of this trade, try finding a grey parrot Psittacus erithacus in Kenya or a scarlet macaw Ara macao in El Salvador; like so many other targets of bird traders, these species no longer occur over significant portions of their former range.

Opting out of such markets is highly attractive for another geopolitical reason. As Cooney \& Jepson point out, the international wild bird trade is not the only recognized threat to bird conservation, it is one of many. But unlike habitat destruction and hunting for food, the legal trade in wild birds is the only major threat created directly by European consumers and the only such threat that can be rapidly and effectively ended with the stroke of a pen in Brussels.

Cooney \& Jepson assert that 'trade bans are necessary and effective tools in specific cases,' and I couldn't agree 
more strongly. Birds are a specific case, being special for three basic reasons: their unique biology, a massive and long-standing demand created by domestic and international markets, and the ease with which millions of exotic birds are now bred in captivity. In general, valuable birds breed slowly, they fly great distances, and they are exquisitely sensitive to disturbance (Thiollay, 1992). Because birds are most efficiently trapped in large congregations, trappers can and do deplete populations from vast regions, causing rapid declines in harvested species. As a group, birds are therefore particularly illsuited for commercial exploitation. For many obvious reasons, Cooney \& Jepson's equating of trade in wild bird with trade in drugs, ivory and tropical fish is simply not appropriate, serving only to confound productive discussion.

Wild bird populations are also challenging and costly to monitor, making it difficult to determine the impacts of harvesting schemes. Monitoring is seldom even attempted. For instance, the Senegal parrot Poicephalus senegalus is the most heavily traded of all CITES Appendix II birds, with combined export quotas of $>35,000$ birds in 2005 (CITES, 2005) and from 2000-2003 over 100,000 individuals were legally exported from West Africa (SSN, 2004). To date, not a single study, population survey or range evaluation has been conducted for this species.

There is one situation where we have a reasonable grasp of the impacts of wild bird trapping: Nicaragua. With CITES support, researchers conducted three country-wide parrot population surveys over the past decade. They measured population sizes of all harvested parrot species, and they did so using methods that controlled for habitat loss (Lezama et al., 2004). Their findings are conclusive and staggering, showing that several harvested parrot species suffered $80 \%$ declines over a 10 year period. Are wild bird harvests sustainable? Where the data are recent and rigorous, the answer is extraordinarily clear. By any definition of the word sustainable this trapping of parrots in Nicaragua, which ranks among the world's most closely controlled and scrutinized, represents an unmitigated failure, akin to strip-mining birds from the forests.

The extraction of blue-fronted amazon Amazona aestiva from Argentina is often touted in these discussions as both 'well managed' (Cooney \& Jepson, 2006) and 'sustainable' (SESDA, 2005). It is the only wild bird harvest to make such claims. Five years ago the Argentine government requested that the USA reopen imports of blue-fronted amazons, as they claimed their management plan satisfied the sustainability clause under the US Wild Bird Conservation Act. In response to this initiative the project received extensive scientific and government review. Based on the management plan, studies of population trends of the blue-fronted amazon, and ongoing harvest practices in Argentina, a group of over 90 parrot researchers urged the USA to reject the proposal and concluded that the 'claims of sustainability are not founded on science of any kind' (Scientists' Letter to FWS, 2003). Their position was supported by 29 regional, national and international NGOs who commented that for these harvests 'the designation of sustainable is meaningless'. More recently, the Argentine government handpicked an established population modeler to predict the sustainability of the blue-fronted amazon harvest (Rabinovich, 2004). Although the model was crippled by a lack of data and ignored essential elements of the programme (the harvest of adults, to name one), it still predicted a threshold for sustainability that was several fold lower than the current legal quota. Put another way, the government's quota was in fact several times greater than the 'sustainable' level predicted by their own modeler.

With $>1,000$ bird species in trade, not a single harvest is demonstrably sustainable. Yet Cooney \& Jepson repeat the pro trade mantra, insisting that the door remain open for the sustainable use of wild birds. Given all the opportunities to develop model programmes, how many decades must we wait for an honest proof-of-concept before we put the final nail in the bird trade coffin? We know that leaving this door open imperils dozens of species and threatens biodiversity in general; how long must we hobble our best efforts with this hypothetical hope?

There is no doubt that there is money to be made from catching and selling wild birds. But who then is making the money and what would they do if the trade ended? As with most products of developing countries, the overwhelming majority of the profits from the wild bird trade are not destined for the producer (in this case the trapper); rather, the profits go primarily to the importers, wholesalers, and retailers in the developed world. Even for valuable birds like grey parrots, we estimate that the trappers receive $<2 \%$ of the proceeds, whereas those on the European side of the trade receive $>80 \%$. When we in the North profit handsomely by trading in the natural heritage of countries in the South, shouldn't we rightly consider this exploitation?

In a few select places and for a few select people, the trapping of wild birds may provide seasonal income. But how do such benefits rank in the big picture, both in terms of the portion of the human population who benefit, and with respect to available alternatives? If one starts with the high figure of 8,300 Tanzanians directly involved in the wild bird trade (Edwards \& Broad, 1992), and contrasts that with a population of 35 million, only 
$0.024 \%$ of the people are involved in the bird trade, about one person in 4,000. Yet of course these birds are the natural heritage of all Tanzanians, and millions there stand to benefit from an ecotourism boom that generates real, sustainable jobs. In terms of long-term value to Tanzanians, surely these birds are worth more in the bush than they are in European living rooms.

I agree that the time has come for the conservation community to address the conservation impacts of the wild bird trade and to seek effective solutions. Cooney \& Jepson have already seen the consequences of such consideration but they appear unwilling to accept the outcome. Among the 240 NGOs that now support the Wild Bird Declaration, Cooney \& Jepson should have noted many of the most important names in bird conservation and nature conservation in general: Defenders of Wildlife, the American Bird Conservancy, Friends of the Earth Europe, Greenpeace, and many others too numerous to list. Signatories also include major national partners of BirdLife International, notably partners in Germany, Belgium, Netherlands, France and the USA. In recent weeks, the UK's BirdLife partner, the Royal Society for the Protection of Birds, has joined the call for a permanent halt to EU imports as well. Seldom do these organizations speak with one voice, yet on the topic of the wild bird trade they have done so, and resoundingly.

Despite Cooney \& Jepson's efforts to repackage the caging of wild birds as a creative and business-savvy solution, the wild bird trade neither alleviates human poverty nor conserves biodiversity. Over the past few decades we have learned that the wild bird trade is both unsustainable and exploitive by nature. Like so many of the repugnant practices of our past, slavery, child labour, and strip-mining, to name a few, we would all do well to move beyond the outdated and unethical caging of wild birds, and wisely leave this practice in the dustbin of previous millennia.

\section{References}

CITES (2005) Convention on International Trade in Endangered Species of Wild Fauna and Flora. Http:// www.cites.org [accessed 21 November 2005].

Cooney, R. \& Jepson, P. (2006) The international wild bird trade: what's wrong with blanket bans? Oryx , 40, 18-23.

Edwards, S. \& Broad, S. (1992) Wild bird trade: perceptions and management in the Republic of Tanzania. In Perceptions, Conservation and Management of Wild Birds in Trade (eds J. Thomsen, S. Edwards \& T. Mulliken), pp. 131-150. TRAFFIC International, Cambridge, UK.

Lezama, M.S., Vilchez, M., Mayorga, R. \& Castellón, R. (2004) Informe de Inventario Nacional de Psitácidos, 2004. Para la Secretaria de la CITES, Nicaragua y Corredor Biológico del Atlántico, Nicaragua. Universidad Centroamericana, Managua, Nicaragua.

Rabinovich, J. (2004) Modeling the Sustainable Use of the Blue-fronted Parrot (Amazona aestiva) in the Dry Chaco Region of Argentina. A Report to the Wildlife Service, Secretary of the Environment and Sustainable Development of Argentina, Buenos Aires.

Scientists' Letter to FWS (2003) Comments to the US Fish and Wildlife Service regarding a proposal to import blue-fronted amazons into the USA under the Wild Bird Conservation Act. Submitted October 2003, signed by 97 parrot researchers. Text and list of signatories available at http:/ / worldparrottrust.org/news/usaamazon.htm [accessed 4 January 2006]

SEDSA (Secretary of the Environment and Sustainable Development of Argentina) (2005) Conservación y aprovechamiento sustentable del loro hablador (Amazona aestiva). Http:/ / www.medioambiente.gov.ar/fauna/ programas/manejo/proyecto_ele/default.htm [accessed 25 October 2005].

SSN (Species Survival Network) (2004) Fast Facts on the Wild Bird Trade and the European Union 2000-2003. Http:/ / www.birdsareforwatching.com/ [accessed 21 November 2005].

Thiollay, J.M. (1992) Influence of selective logging on bird species diversity in a Guianan rain forest. Conservation Biology, 6, 47-63.

Wild Bird Declaration (2004) The European Union Wild Bird Declaration. An NGO Call to Halt Wild Bird Imports into the European Union. 223+ signatory organizations. Http:/ / www.worldparrottrust.org/trade/wildbirddec/wbdec.pdf [accessed 25 October 2005]. 